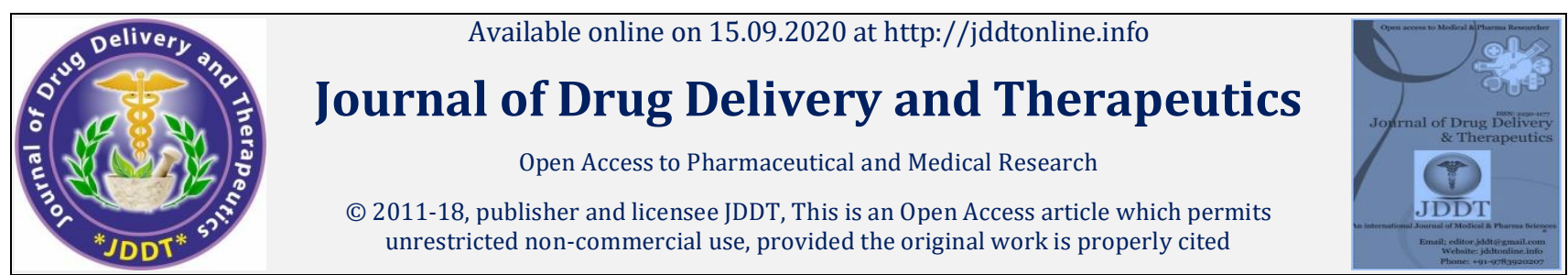

Open $\odot$ Access

Research Article

\title{
Epidemiological, Clinical, Histological, Serological and Therapeutic Study of Children Celiac Disease in Western Algeria Region
}

\section{Dounia Zad EL MEHADJI ${ }^{*}$, Khalida ZEMRI' ${ }^{1}$, Hayet MEHIDA ${ }^{1}$, Noria HARIR ${ }^{1}$, Djamila YEKROU ${ }^{2}$, Karim Bouziane NEDJADI ${ }^{3}$, Charef LATROCH $^{3}$, Siheme OUALI ${ }^{1}$, Zahira BENAISSA ${ }^{1}$}

1. Laboratory of Molecular Microbiology, Proteomics and Health. Department of Biology, Djillali Liabes University of Sidibel Abb es, (Ex ITMA), Algeria

2. Departement of Medical Oncology, Anti-Cancer Centre of Sidi Bel Abbes. Algeria

3. Departement of Pediatrics « $\mathrm{C} »($ A. Cabral), CHU of Oran, Algeria

\begin{abstract}
Objectives: To determine the epidemiological, clinical, histological, serological and therapeutic profile of celiac disease in children in Western Algeria region.

Methods: 250 patients over a period of three years (2016 - 2019) from the pediatric department of the University Hospital of Oran (West Algeria) were included in our retrospective study.

Results: We noticed a female predominance with a sex ratio $\mathrm{F} / \mathrm{M}=1.57$. Symptoms were defined by typical $(73.2 \%)$ and atypical $(26.8 \%)$ forms, digestive disorders (47.2\%), extra digestive disorders (14.4\%). Anemia was noted at $73.6 \%$, and the association with au toimmune diseases at $14.8 \%$. Seropositivity was present in $77.6 \%$ of cases and histology revealed partial grade villous atrophy at $54 \%$. We noticed a significant link between the histological grade and the serology $(p=0.001)$, between age and histological grade $\left(p<10^{-3}\right)$, between bone age and body mass index $(p=0.017)$, between the age of onset of the disease and the age of food diversification ( $p=0.030)$, and with the age of breastfeeding $(p=0.026)$. In addition, we found an excellent correlation between anti-transglutaminase and anti-endomysium autoantibodies during diagnosis and under diet $\left(\mathrm{p}<10^{-3}\right)$, and between serology during diagnosis and serology under diet $(\mathrm{p}=0.002)$

Conclusion: Celiac disease (CD) of children in western Algeria is characterized by a variety of clinical symptoms. The gluten-free diet remains the only therapy for these affected children.

Keywords: celiac disease, children, epidemiology, serology, histology, associated diseases, treatment.
\end{abstract}

Article Info: Received 17 July 2020; Review Completed 12 August 2020; Accepted 19 August 2020; Available online 15 September 2020

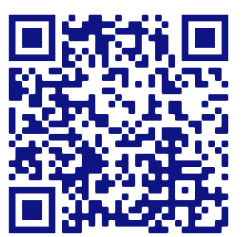

\section{Cite this article as:}

El Mehadji DZ, Zemri K, Mehida H, Harir N, Yekrou D, Nedjadi KB, Latroch C, Ouali S, Benaissa Z, Epidemiological, Clinical, Histological, Serological and Therapeutic Study of Children Celiac Disease in Western Algeria Region, Journal of Drug Delivery and Therapeutics. 2020; 10(5):6-10 http://dx.doi.org/10.22270/jddt.v10i5.4344

Dounia Zad EL MEHADJI, PhD Candidate in Biochemistry-Immunology, Laboratory of Molecular Microbiology, Proteomics and Health. Department of Biology, Djillali Liabes University of Sidibel Abbes, (Ex ITMA), Algeria

\section{INTRODUCTION}

Celiac disease is an autoimmune-mediated enteropathy, which occurs in genetically susceptible individuals 1 . It is a chronic, systemic and inflammatory pathology characterized by villous atrophy of the small intestine induced by a food antigen, prolamins (gluten) ${ }^{2,3}$. The frequency of the disease is worldwide even if the disease goes undiagnosed 4 , the incidence of the disease has increased in recent decades. Celiac disease is a major public health problem affecting $1 \%$ $3 \%$ of children 5,6 . According to screening studies in children, the prevalence varies between 3 and 14/1000 7, 8 while in Sahrawi children in Algeria the prevalence is exceptional, it is 56/1000 9. This disease manifests itself at any age and the clinical presentation is defined by a variety of symptoms 10 . The symptomatologies of the disease of classic form are the most typical and are defined by the gastrointestinal manifestations (GT), but also, can have extra intestinal manifestations 11-13. Through this study we aim to understand the parameters identifying this disease ISSN: 2250-1177 nevertheless the epidemiological, serological, clinical and histological profile in children of the region of Western Algeria.

\section{PATIENTS AND METHODS}

\section{The population:}

We have established a retrospective epidemiological study, in the pediatric department, Saint-Michel, of Oran region (western Algeria), bringing together 250 patients with celiac disease over a period of three years (2016-2019). Only CD children having performed serological and histological analyzes and aged less than 16 years were included in our survey. The following variables were considered: age; sex; disease duration; serological and histological assessment; comorbidities; age of disease onset; the age of the gluten-free diet; age of dietary diversification and the age of introduction of gluten; and treatments. 


\section{The statistical analysis:}

Concerning the statistical analytical study, data were summarized using rates and cross-tabulations. For the Associations between different parameters the Pearson's Khi2 test $\left(\chi^{2}\right)$ was used to evaluate the statistical significance $(\mathrm{P}<0.05)$. All data were processed and analyzed via SPSS 22.0 (Statistical Package for the Social Sciences, IBM Corporation; Chicago, IL. August 2013).

\section{RESULTS:}

250 cases were enrolled in our study between 2016-2019 $(61.2 \%$ females and $38.8 \%$ males $)$. A clear female predominance was noted with the female to male ratio of 1.57 , the median age was of $5.10 \pm 3.82$ running from 6 month to 13 years old.

In our population, the average age of onset of the disease was at $3.44 \pm 3.34$ years, while that of introduction of gluten was at $6.37 \pm 2.19$ months. However, the average age at the start of dietary diversification in our children was at $5.36 \pm 1.58$ months.

Birth weight was within range for all patients and the median body mass index was at $15.32 \pm 2.57 \mathrm{~kg} / \mathrm{m} 2.25 \%$ of celiac children were from consanguineous marriage and $24.4 \%$ had a family history of the disease (Table 1 ).

Celiac disease was typical in $73.2 \%$ of cases and atypical in $26.8 \%$. Symptoms were defined as digestive disorders (47.2\%): chronic diarrhea $64.8 \%$, abdominal pain $52.4 \%$, vomiting $37.6 \%$ and abdominal bloating in $34.4 \%$ of cases. Extra digestive manifestations were noted in $14.4 \%$ of patients: such as weight loss at $38.4 \%$, anemia at $30 \%$ and failure to thrive at $35.6 \%$. Bone age was consistent with chronological age in $60 \%$ of the children.

Pathological examination of the duodeno-jejunal biopsy showed the presence of partial grade villous atrophy at $54 \%$, subtotal at $23.6 \%$ and total at $12 \%$. According to Marsh's classification, stage 3 was dominant in $29.2 \%$ of patients, with a rate of intraepithelial lymphocytes greater than or equal to $30 \%$ in $46 \%$. $77.6 \%$ of cases presented a positive serology. In fact, the seropositivity of the antitransglutaminase isotype IgA, IgG auto-antibodies assay was noted in $68 \%$ and $76.8 \%$ respectively. Likewise, anti-gliadins of isotype IgA were positive at $88.4 \%$ and anti-endomysium in $87.6 \%$ of cases (table 2).

$73.6 \%$ of the children developed anemia with an average hemoglobin $(10.78 \pm 1.77 \mathrm{~g} / \mathrm{dl}), 8 \%$ an allergy to cow's milk proteins (CMPA), 5.6\% thyroid disorders and $2.4 \%$ asthma. However, we noted an association with autoimmune diseases at $14.8 \%$ (thyroiditis at $6.8 \%$, Type I Diabetes at $3.2 \%$,IgA deficiency at $2.8 \%$,linear IgA dermatosis $1.2 \%$ and psoriasis at $0.8 \%$ of cases). The gluten-free diet was prescribed for all patients as the only treatment for this disease but sometimes combined with symptomatic treatments to treat digestive disorders and anemia. Almost $65.2 \%$ of cases followed the diet well and serological analysis after two years on the diet showed negativity in $76 \%$ of cases with an average body mass index of $17.20 \pm 3.08 \mathrm{~kg} / \mathrm{m} 2$.

Statistical analysis showed the existence of a significantly increased correlation link between the origin and the socioeconomic level of patients ( $p=0.003)$, between bone age and body mass index $(p=0.017)$, between the age of onset of the disease and the age of food diversification $(p=0.030)$, and with the age of breastfeeding $(p=0.026)$. We also noted a correlation between age and histological grade $(p<10-3)$. Likewise, a very significant correlation between age and age of disease onset $(p<10-3)$, age and age of gluten-free diet $(p<10-3)$ and also the age of disease onset was correlated with the age of onset of the gluten-free diet $(\mathrm{p}<10-3)$. In addition, we found an excellent correlation between antitransglutaminase and anti-endomysium autoantibodies during diagnosis and under diet $(\mathrm{p}<10-3)$, and between serology during diagnosis and serology under diet $(\mathrm{p}=$ 0.002) (table 3).

Chi-square test also showed a significant association between histological grade and serology $(p=0.028)$ (figure1).

\begin{tabular}{|lc|}
\hline \multicolumn{2}{|c|}{ Table 1 : Characteristics of population } \\
\hline Number (\%) & \\
\hline Gender, n (\%) & $153(61.2 \%)$. \\
Female & $97(38.8 \%)$. \\
Male & \\
\hline Personal history, n (\%) & $20(8 \%)$. \\
Medical staff, n (\%) & $14(5.6 \%)$. \\
Anemia & $8(3.2 \%)$. \\
Notion of prematurity & $6(2.4 \%)$. \\
Type I diabetes & $2(0.8 \%)$. \\
Allergy & $1(0.4 \%)$. \\
& $1(0.4 \%)$. \\
Surgical personnel, $n(\%)$ & $61(24.4 \%)$. \\
Appendectomy & $63(25.2 \%)$. \\
Cholecystectomy & \\
Ectopitesticular & $26(10.4 \%)$. \\
\hline Family history of CD, $\mathbf{n}(\%)$ & $70(28 \%)$. \\
Consanguinity of parents, $n(\%)$ & $154(61.6 \%)$. \\
\hline Socio-economic level n, (\%) & \\
Good & \\
Bottom & \\
Medium & \\
\hline CD: celiac disease & \\
\hline
\end{tabular}




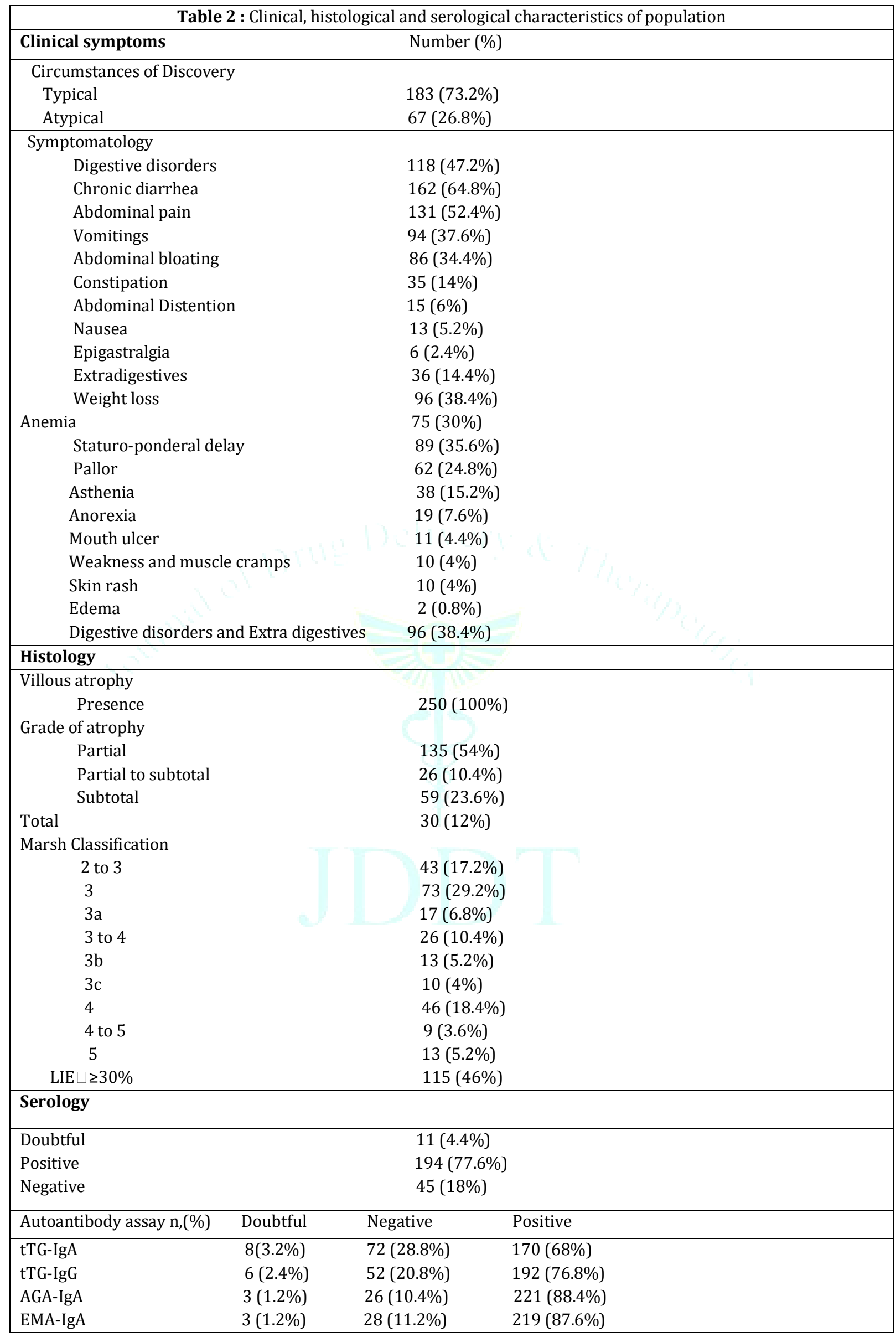


Table 3: the correlation between the age of onset of the disease and different parameters

\begin{tabular}{|c|c|c|c|}
\hline \multirow[t]{2}{*}{ Variable } & \multicolumn{3}{|c|}{ Age of onset of the disease } \\
\hline & $\mathrm{n}$ & r (corrélation coefficient) & $\mathrm{p}$ \\
\hline Age of dietary diversification & \multirow{3}{*}{250} & $0.137^{*}$ & 0.030 \\
\hline Breast feeding age & & $0.141^{*}$ & 0.026 \\
\hline Age on Gluten-Free Diet & & $0.703^{* *}$ & $<10^{-3}$ \\
\hline & \multicolumn{2}{|c|}{ Age range } & \\
\hline Age of onset of the disease & \multirow{3}{*}{250} & $0.670^{* *}$ & $<10^{-3}$ \\
\hline Histological grade & & $0.270^{* *}$ & $<10^{-3}$ \\
\hline Age on Gluten-Free Diet & & $0.765^{* *}$ & $<10^{-3}$ \\
\hline \multicolumn{4}{|l|}{ Origin } \\
\hline Socio-economic level & 250 & $0,187^{* *}$ & 0,003 \\
\hline \multicolumn{4}{|l|}{ bone age } \\
\hline Body mass index & 250 &,$- 152^{*}$ & 0,017 \\
\hline \multicolumn{4}{|l|}{ Anti-transglutaminase } \\
\hline Anti-endomysial & 250 & $0,746^{* *}$ & $<10^{-3}$ \\
\hline \multicolumn{4}{|l|}{ Serology under regimen } \\
\hline Serology at diagnosis & 250 & $0,198^{* *}$ & 0,002 \\
\hline
\end{tabular}

Chi-square test shows a significant association between associated diseases and associated autoimmune diseases $\left(p<10^{-3}\right)$,The results are not significant between symptomatology and histology, histological grade and serology( $\mathrm{p}=0.028)$ Figure 1 illustrates the significance between serology and histology

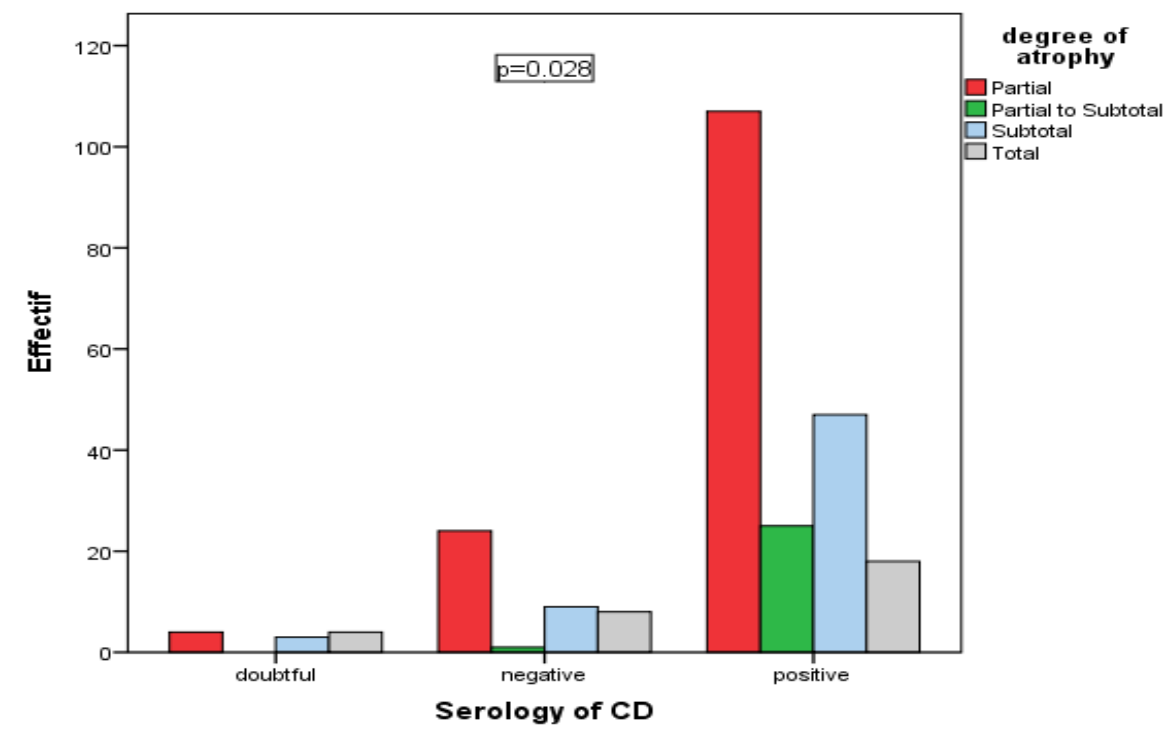

Figure 1: Distribution of patients according to significance between serology and histology

\section{DISCUSSION}

At the end of our study, celiac disease was characterized by a clear predominance of the female sex with a sex ratio of 1.57 . This predominance was also underlined by other studies 14 . Celiac disease can be diagnosed at any age but presents as an atypical form in adolescents and adults ${ }^{10}$. In our study, the mean age of onset of the disease was $3.44 \pm 3.34$ years which agrees with the results of 15 in eastern Algeria. Nevertheless, the diagnosis of the disease is essentially based on a recombination of histological, serological, clinical criteria and the response to the gluten-free diet 12,16; this was well indicated and confirmed by our results. The literature suggests that the symptomatology of the disease appears in children when gluten is introduced and more precisely at the age of onset of dietary diversification as well as when breastfeeding is stopped 15,17 which is consistent with our results. Thus, breastfeeding plays a protective role against this pathology.
The clinical presentation showed the predominance of the classic (typical) form, at 73.2\%, while the atypical form was noted at $26.8 \%$, characterized by gastrointestinal or extraintestinal manifestations, respectively. This result is consistent with the data noted in the studies of A. S. McNeish et al ${ }^{16}$ and J. F. Ludvigsson et al ${ }^{18}$. Chronic diarrhea (64.8\%) and abdominal pain $(52.4 \%)$ and vomiting (37.6\%) were the most frequent disorders in our sample, which is in agreement with a study conducted in Sudan which noted chronic diarrhea as the main characteristic of the disease in children ${ }^{19}$. However and in a comparable way in the region of eastern Algeria, children presented abdominal pain as the main symptom ${ }^{15}$. The disease is defined by a diversity of symptoms, mainly digestive disorders, these data are also confirmed by our results 15,20 . In addition, and in association with digestive disorders, we particularly observed the symptoms of weight loss at $38.8 \%$, anemia at $36.8 \%$, failure to thrive at $36 \%$ and mucocutaneous paleness at $25.6 \%$. 
Which confirms that celiac disease can manifest itself from intestinal or extra intestinal manifestations 11 in children and Adolescents.

Celiac disease promotes the development of many pathologies, the most common in our series was anemia at $73.6 \%$. These data are similar to those of 21,22 . Therefore, our results underline that anemia is a complication of celiac disease, which can be either related to nutritional status (weight loss) or to hematological disorders 23. CD was associated with more than one autoimmune disease defining multiple autoimmune syndrome, its association with autoimmune diseases is highlighted primarily with type I diabetes and thyroiditis as reported in the literature 1,24.

This study confirms that the histological examination is the main test and is done by a duodenojejunal biopsy. Partial grade villous atrophy and Marsh classification 3 was noted in most of our patients, confirming the results of the study by ${ }^{25}$. Likewise, serological tests are considered to be the most reliable for detection of the disease and even are recommended in screening ${ }^{26}$. Indeed, the positivity of the serology is essential for the diagnosis to be acquired. In our work, this positivity was found in $77.6 \%$ of patients. We noticed a significant link between the histological grade and the serology ( $p=0.001)$, which is consistent with the findings of the study conducted in eastern Algeria 15. Similarly, an excellent correlation between antitransglutaminase and anti-endomysium autoantibodies has been revealed, which confirms their specificity and sensitivity, thus joining the results of P. Roujon et al 27 .

The treatment of the disease is based on diet, in our study all the patients were advised to follow a gluten-free diet. According to the literature, the gluten-free diet remains the only effective treatment for the disease but remains difficult to maintain 26,28 . Compliance with the gluten-free diet was assessed by self-report of patients with reported deviations from the diet and by the presence of clinical signs.

\section{CONCLUSION:}

According to our results, the clinical presentation of celiac disease in Algerian children (west Algeria) is also defined by typical and atypical forms with intestinal or extra intestinal symptoms respectively and the gluten exclusion diet remains the major element for the success of the dietary management. A prospective study should be carried out at the long term in different regions of our country to validate and compare the different characteristics of celiac disease in children, as well as to study the factors predisposing the Algerian population to this pathology.

\section{REFERENCES:}

1. Lundin KEA et C. Wijmenga. Coeliac disease and autoimmune disease-genetic overlap and screening. Nat RevGastroenterolHepatol, 2015; 12(9):507-515.

2. Husby S, Koletzko S, Korponay-Szabó IR, et al. European Society for Pediatric Gastroenterology, Hepatology, and Nutrition guidelines for the diagnosis of coeliac disease , J. Pediatr. Gastroenterol. Nutr, 2012; 54(1):136-160.

3. M. F. Kagnoff. Celiac disease:pathogenesis of a model immunogenetic disease .J. Clin. Invest, 2007; 117(1):41-49.
4. Green FHR et C. Cellier. Celiac disease . N. Engl. J. Med. 2007; 357(17):1731-1743.

5. Mäki M, Mustalahti K, Kokkonen J, et al. Prevalence of Celiac disease among children in Finland. $N$ Engl J Med. 2003; 348(25):2517-2524.

6. Myléus A, Ivarsson A, Webb C, et al. Celiac disease revealed in $3 \%$ of Swedish 12-year-olds born during an epidemic. J Pediatr Gastroenterol Nutr. 2009;49(2):170-176.

7. Catassi C et al. Coeliac disease in the year2000:exploring the iceberg. Lancet, 1994; 343:200-203.

8. Korponay-Szabó IR, Szabados K, Pusztai J, et al. Population screening for coeliac disease in primary care by district nurses using a rapid antibody test: diagnostic accuracy and feasibility study. BMJ. 2007; 335 (7632):1244-1247.

9. Catassi C et al. Why is coeliac disease endemic in the people of the Sahara? . Lancet, 1999; 354(9179):647-648.

10. Fasano A et C. Catassi. Coeliac disease in children . Best PractRes Clin Gastroenterol, 2005; 19(3):467-478.

11. Saeed A, Assiri AM, et H. A. Cheema. Celiac Disease in Children ,2019; 2(1):6.

12. Verkarre $\mathrm{V}$, et $\mathrm{N}$. Brousse. Le diagnostic histologique de la maladie cœliaque. Pathologie Biologie, 2013; 61(2):e13-e19.

13. S. J. Gluten-free diet for children. Pathologie-biologie, 2013.

14. Kivelä L, Kaukinen K, Lähdeaho ML, et al. Presentation of Celiac Disease in Finnish Children Is No Longer Changing: A 50-Year Perspective. J Pediatr. 2015; 167(5):1109-15.e1.

15. Abed N, N. el houdaCherouat, H. Mohammedi, A. Rouabah, et L. Rouabah. Characteristics of Celiac Disease in Childhood of Eastern Algeria. Advanced Research in Life Sciences, 2019; 3(1):5-10.

16. McNeish AS, Harms HK, Rey J, Shmerling DH, Visakorpi JK, Walker-Smith JA. The diagnosis of coeliac disease. A commentary on the current practices of members of the European Society for Paediatric Gastroenterology and Nutrition (ESPGAN). Arch Dis Child. 1979; 54(10):783-786.

17. H. Garnier-Lengliné, G. Malamut, N. Cerf-Bensussan, et F. M. Ruemmele. Treatment perspectives. Pathol. Biol, 2013; 61( 3): e61-64.

18. Ludvigsson JF et al. The Oslo definitions for coeliac disease and relatedterms . Gut, 2013; 62(1):43-52.

19. A. K. Ahmed, R. M. A. Elhafiz, A. S. Almubarak, et M. A. Ali. Frequency Rate of Celiac Disease in Sudanese Patients presenting with Chronic Diarrhea . African Journal of Medical Sciences, 2018; 3(4).

20. Hill ID, Dirks MH, Liptak GS, et al. Guideline for the diagnosis and treatment of celiac disease in children: recommendations of the North American Society for Pediatric Gastroenterology, Hepatology and Nutrition. J Pediatr Gastroenterol Nutr. 2005; 40(1):1-19.

21. F. Boukezoula, S. Smaali, et M. Zidoune. Prevalence of Anemia in a Population with Celiac Disease in Tébessa (Algeria), 2018; 5.

22. A. Albrady. Clinical Profile of Celiac Disease: Patient Epidemiological Prospective. Annals of Medical and Health Sciences Research, 2018; 8(1):5.

23. J. Cosnes et I. Nion-Larmurier. Les complications de la maladie cœliaque .Pathologie Biologie, 2013; 61(2):e21-e26.

24. Lauret E et L. Rodrigo. Celiac Disease and AutoimmuneAssociated Conditions .BiomedRes Int, 2013; 2013.

25. Castro-Antunes MM, Magalh\&atilde;es R, Nobre JMM, Silva BP, et G. A. P. Silva. Celiac disease in first-degree relatives of patients. J Pediatr (Rio J), 2010; 86(4):331-336.

26. AGA Institute. AGA Institute Medical Position Statement on the Diagnosis and Management of Celiac Disease. Gastroenterology 2006; 131(6):1977-1980.

27. Roujonet $P$ al. Diagnostic sérologique de la maladie cœliaque .Pathologie Biologie, 2013; 61(3):e39-e46.

28. Farrell RJ, et C. P. Kelly. Celiac sprue . N. Engl. J. Med, 2002; 346(3):80-188. 